algorithms. Braz J Med Biol Res. 2016;49. doi:10.1590/1414-431X20165206

6. Yoshida $\mathbf{N}$, Inden $\mathbf{Y}$, Uchikawa $T$, et al. Novel transitional zone index allows more accurate differentiation between idiopathic right ventricular outflow tract and aortic sinus cusp ventricular arrhythmias. Heart Rhythm. 2011;8(3):349-356. doi:10.1016/j.hrthm.2010.11.023

7. Betensky BP, Park RE, Marchlinski FE, et al. The V(2) transition ratio: a new electrocardiographic criterion for distinguishing left from right ventricular outflow tract tachycardia origin. J Am Coll Cardiol. 2011;57(22):2255-2262. doi:10.1016/j.jacc.2011.01.035

8. Yoshida N, Yamada T, Mcelderry HT, et al. A Novel Electrocardiographic Criterion for Differentiating a Left from Right Ventricular Outflow Tract Tachycardia Origin: The V2S/V3R Index: V2S/V3R Index Distinguishes LVOT from RVOT Origins. Journal of Cardiovascular Electrophysiology. doi:10.1111/jce.12392

\title{
NHẬN XÉT ĐIỀU TRỊ NANG VÀ ÁP-XE TUYẾN BARTHOLIN TẠI BỆNH VIỆN PHỤ SẢN TRUNG ƯƠNG
}

\section{TÓM TẮT}

Mục tiêu: Nhân xét một số đặc điểm về lâm sàng, cận lầm sàng; kết quả điều trịbệnh lý nang và áp-xe tuyến Bartholin tại Bệnh viện phụ sản Trung ương (BVPSTƯ). Phương pháp nghiên cứu: mô tả tiến cứu. Kết quả: Tuối trung bình của phụ nữ có bệnh lý tuyến Bartholin là $37,2 \pm 1,1$ tuổi. Có triểu chứng "đau" trong 78,6\% các trường hợp. Tỷ lệ thủ thuật "bóc tuyến" là $97,4 \%$ với điều trị nang tuyến Bartholin; trong điêu trị áp-xe tuyến Bartholin "chích khâu viền khăn" chiếm 90,3\%, "rach thoát dich" 9,7\%. Về kết quả điều trị: thủ thuật "chích khâu viên khăn" tái phát $20 \%$, di chứng seo cứng 16,7\%; "rạch thoát dịch" tái phát 33,3\%, di chứng sẹo cứng 33,3\%; "bóc tuyến" tái phát $5,3 \%$, di chứng seo cứng $5,3 \%$, đau khi giao hợp $2,6 \%$ và có tai biến chảy máu, tụ máu sau bóc là 5,2\%. Kết luận: phụ nữ mắc bệnh nang, áp-xe tuyến Bartholin chủ yếu trong độ tuổi sinh sản; "đau" là triệu chứng lâm sàng phố biến nhất trong bệnh lý tuyến Bartholin. Thủ thuật "bóc tuyến" chiếm tỷ lệ cao 97,4\% trong điều trị nang tuyến Bartholin; với tỷ lệ tái phát thấp $(5,3 \%)$ và ít di chứng. "Chích khâu viền khăn" chiếm tỷ lệ chủ yếu $(90,3 \%)$ trong điều trị ápxe tuyến Bartholin, với tỷ lệ tái phát và di chứngcao hơn nhiều so với bóc tuyến.

Tư khóa: nang tuyến Bartholin, áp-xe tuyến Bartholin.

\section{SUMMARY}

\section{COMMENTARY RESULTS TREATMENT OF BARTHOLIN GLAND CYSTS AND ABSCESSESAT THE NATIONAL HOSPITAL OF OBSTETRICS AND GYNECOLOGY}

Objectives: To review some clinical and subclinical characteristics and results in the treatment

\footnotetext{
${ }^{1}$ Bệnh viện đa khoa huyện Kim Sơn ${ }^{2}$ Đai hoc Y Hà Nôi

Chịu trách nhiệm chính: Nguyễn Bích Hồng

Email: nguyenbichhongnb@gmail.com

Ngày nhân bài: 3.8.2021

Ngày phản biên khoa hoc: 4.10 .2021

Ngày duyệt bài: 14.10.2021
}

\section{Nguyễn Bích Hồng ${ }^{1}$, Lê Thị Thanh Vân ${ }^{2}$}

of Bartholin gland cysts and abscesses at the National Hospital of Obstetrics and Gynecology. Methodology: Prospective descriptive. Results: The mean age of women with Bartholin gland disease was 37.2 \pm 1.1 years. There are symptoms of pain in $78.6 \%$ of cases. The rate of treatment technique, excision is $97.4 \%$ with Bartholin's cysts; in the treatment of Bartholin gland abscesses, marsupialization accounted for $90.3 \%$ and the procedure is $9.7 \%$. About the treatment results: the technique of marsupialization has a recurrence of $20 \%$, the sequelae of hard scars are $16.7 \%$; recurrence of the procedure is $33.3 \%$, sequelae of hard scars is $33.3 \%$; recurrence of excision is $5.3 \%$, sequelae of hard scarring $5.3 \%$, pain during intercourse $2.6 \%$ and there were bleeding complications, hematoma after peel was $5.2 \%$. Conclusion: women with Bartholin's gland disease are mainly of reproductive age; pain is the most common clinical symptom in Bartholin gland disease. The technique of excision accounts for a high rate of $97.4 \%$ in the treatment of Bartholin's cysts; with a low recurrence rate $(5.3 \%)$ and few sequelae. The technique of marsupialization accounts for $90.3 \%$ in the treatment of Bartholin gland abscess, with a higher rate of recurrence and sequelae than the excision technique.

Key words: Bartholin's gland cysts, bartholin's gland abscesses.

\section{I. ĐĂT VẤN ĐỀ}

Tuyến Bartholin là tuyến tiên đình lớn ở phụ nữ (giống như tuyến hành niệu đạo ở nam giới), gồm 2 tuyến nhỏ như hạt đậu ở hai bên âm hộ vị trí 4h-8h; có ống tuyến tiết dịch đổ vào âm đạo trong khi giao hợp. Bệnh lý tuyến Bartholin (chủ yếu là nang và áp-xe) khá phổ biến, $2 \%$ phụ nữ từng trải qua bệnh lý tuyến Bartholin trong cuộc đời họ ${ }^{1}$. Nang tuyến Bartholin do tắc và giãn ống. Sự tắc nghẽn có thể do nhiễm trùng hoặc không do nhiễm trùng; nhiễm trùng có thể tồn tại mạn tính và tái phát từng đợt. Áp-xe tuyến Bartholin có thể phát triển từ một ổ nhiễm 
trùng tiên phát hoặc thứ phát từ nang tuyến Bartholin. Nó liên quan đến phản ứng viêm cấp bao quanh ống và có mủ trong lòng áp-xe ${ }^{2}$. Hiện nay, có nhiêu thủ thuật điều trị nang và áp-xe tuyến Bartholin: rạch thoát dịch, chích khâu viền khăn, xơ hóa bằng cồn, loại bỏ tuyến bằng Nitrat bạc, đặt ống Word dẫn lưu, bóc tuyến... với tỷ lệ tái phát từ $2 \%$ đến $25 \%{ }^{1}$. Sự cải tiến kỹ thuật trong điều trị bệnh lý tuyến Bartholin nhằm giảm tái phát và di chứng, nâng cao chất lượng cuộc sống người phụ nữ sau phẫu thuật. Vì vậy, chúng tôi tiến hành nghiên cứu này, nhằm nhận xét điều trị của một số thủ thuật ngoại khoa, được áp dụng tại BVPSTU trên những bệnh nhân có nang, áp-xe tuyến Bartholin.

\section{II. ĐỐI TƯƠNGG VÀ PHƯƠNG PHÁP NGHIÊN CỨU \\ 2.1 Đối tượng nghiên cứu:}

- Tiêu chuẩn lựa chọn: Những bệnh nhân có bênhh lý tuyến Bartholin, điều trị tại bệnh viện BVPSTU từ tháng 9/2020 đến tháng 9/2021, thỏa mãn các tiêu chí: có đầy đủ các xét nghiệm cần thiết theo mẫu bệnh án nghiên cứu(công thức máu, sinh hóa máu, soi tươi dịch âm đạo); được chẩn đoán nang, áp-xe tuyến Bartholin và điều trị bằng các thủ thuật ngoại khoa.Bệnh nhân đồng ý tham gia nghiên cứu.

- Tiêu chuẩn loại trừ: bệnh nhân có bệnh lý tuyến Bartholin đang rong kinh, rong huyết; mắc các bệnh lý cấp tính đe dọa tính mạng (đột quy. não, suy gan cấp, hôn mê,...)

2.2 Phương pháp nghiên cứu: Nghiên cứu mô tả tiến cứu.

2.3 Cỡ mẫu nghiên cứu:

Bảng 2: Tỷ lệ triệu chứng lâm sàng, cận lâm sàng với mỗi hình thái tổn thương.

\begin{tabular}{|c|c|c|c|c|c|c|c|}
\hline & \multicolumn{6}{|c|}{ Triệu chứng lâm sàng, cận lâm sàng } & \multirow[b]{2}{*}{ Tổng } \\
\hline & $\begin{array}{l}\text { Có "sờ } \\
\text { thấy khối" }\end{array}$ & $\begin{array}{l}\text { Có "viêm } \\
\text { đỏ" }\end{array}$ & Có "đau" & $\begin{array}{l}\text { Có "rò } \\
\text { mủ" }\end{array}$ & Có "sốt" & $\begin{array}{l}\text { Có "băch } \\
\text { câu tăng" }\end{array}$ & \\
\hline N(\%) & $52(74,3 \%)$ & $34(48,6 \%)$ & $55(78,6 \%)$ & $5(7,1 \%)$ & $3(4,3 \%)$ & $25(35,7 \%)$ & $70(100 \%)$ \\
\hline \begin{tabular}{|c|} 
Nang tuyến \\
Bartholin N(\%) \\
\end{tabular} & $\begin{array}{c}35 \\
(92,1 \%) \\
\end{array}$ & $\begin{array}{c}7 \\
(18,4 \%)\end{array}$ & $\begin{array}{c}24 \\
(63,2 \%) \\
\end{array}$ & $\begin{array}{c}0 \\
(0 \%) \\
\end{array}$ & $\begin{array}{c}0 \\
(0 \%) \\
\end{array}$ & $\begin{array}{c}6 \\
(15,8 \%)\end{array}$ & $\begin{array}{c}38 \\
(100 \%) \\
\end{array}$ \\
\hline $\begin{array}{c}\text { Ap-xe tuyến Bartholin } \\
\mathrm{N}(\%)\end{array}$ & $\begin{array}{c}17 \\
(54,8 \%)\end{array}$ & $\begin{array}{c}26 \\
(83,9 \%)\end{array}$ & $\begin{array}{c}30 \\
(96,8 \%)\end{array}$ & $\begin{array}{c}5 \\
(16,1 \%)\end{array}$ & $\begin{array}{c}3 \\
(9,7 \%)\end{array}$ & $\begin{array}{c}19 \\
(61,3 \%)\end{array}$ & $\begin{array}{c}31 \\
(100 \%)\end{array}$ \\
\hline
\end{tabular}

Nhận xét: Triệu chứng "đau" chiếm tỷ lệ : 78,6\% trong tống số bệnh nhân, với những bệnh nhân áp-xe tuyến Bartholin, $96,8 \%$ có đau; $83,9 \%$ có viêm đỏ. Với nang tuyến Bartholin, triệu chứng "sờ thây khối" $92,1 \%$, triêuu chứng đau chiếm $63,2 \%$.

Bảng 3: Phân bồ kỹ thuật điều trị ngoại khoa theo chẩn đoán bệnh

\begin{tabular}{|c|c|c|c|c|c|}
\hline \multirow[b]{2}{*}{ Chẩn đoán } & \multicolumn{3}{|c|}{ Điều trị ngoại khoa } & \multirow[b]{2}{*}{ Tổng số } & \multirow{6}{*}{$P<0,05$} \\
\hline & $\begin{array}{l}\text { Chích khâu } \\
\text { viền khăn }\end{array}$ & Bóc tuyến & $\begin{array}{l}\text { Rạch thoát } \\
\text { dich }\end{array}$ & & \\
\hline Nang tuyến Bartholin & $1(2,6 \%)$ & $37(97,4 \%)$ & $0(0 \%)$ & $38(100 \%)$ & \\
\hline Áp-xe tuyến Bartholin & $28(90,3 \%)$ & $0(0 \%)$ & $3(9,7 \%)$ & $31(100 \%)$ & \\
\hline Nang+áp-xe tuyến Bartholin & $1(50 \%)$ & $1(50 \%)$ & $0(0 \%)$ & $2(100 \%)$ & \\
\hline Tổng số & $30(42,3 \%)$ & $38((53,5 \%)$ & $3(4,2 \%)$ & $71(100 \%)$ & \\
\hline
\end{tabular}


Nhận xét: Kỹ thuật "bóc tuyến" chiếm 97,4\% trong số 38 bệnh nhân nang tuyến Bartholin; "chích khâu viền khăn" chiếm 90,3\%, "rạch thoát dịch" chiếm 9,7\% trong số 31 bệnh nhân áp-xe tuyến Bartholin. Có 1 bệnh nhân được chẩn đoán nang và áp-xe tuyến Bartholin, được bóc tuyến và chích khâu viên khăn. $(p<0,05)$

Bảng 4: Tỷ lệ các tai biến trong bóc tuyến Bartholin.

\begin{tabular}{|c|c|c|}
\hline Tai biến & Số lượng (n) & Tỷ lệ (\%) \\
\hline Chảy máu sau mố & 1 & 2,6 \\
\hline Tụ máu sau mố & 1 & 2,6 \\
\hline Không tai biến & 36 & 94,8 \\
\hline Tống & 38 & 100 \\
\hline
\end{tabular}

Nhận xét: Trong 38 tốn thương được bóc tuyễn 2,6\% chảy máu sau mố; 2,6\% tụ máu sau mố. Còn lại 94,8\% các trường hợp không có tai biến.

\begin{tabular}{|c|c|c|c|c|c|c|c|}
\hline \multirow{2}{*}{$\begin{array}{c}\text { Điêu trị } \\
\text { ngoại khoa }\end{array}$} & \multicolumn{2}{|c|}{ Tái phát } & \multicolumn{3}{|c|}{ Di chứng } & \multirow{2}{*}{$\begin{array}{l}\text { Tổng } \\
\text { Số }\end{array}$} & \multirow{6}{*}{$P<0,05$} \\
\hline & Không & Có & $\begin{array}{l}\text { Không di } \\
\text { chứng }\end{array}$ & $\begin{array}{c}\text { Seo } \\
\text { cứng }\end{array}$ & $\begin{array}{l}\text { Đau khi } \\
\text { giao hơp }\end{array}$ & & \\
\hline $\begin{array}{l}\text { Chích khâu } \\
\text { viền khăn }\end{array}$ & $\begin{array}{c}24 \\
(80 \%) \\
\end{array}$ & $\begin{array}{c}6 \\
(20 \%) \\
\end{array}$ & $\begin{array}{c}25 \\
(83,3 \%) \\
\end{array}$ & $\begin{array}{c}5 \\
(16,7 \%) \\
\end{array}$ & $\begin{array}{c}0 \\
(0 \%)\end{array}$ & $\begin{array}{c}30 \\
(100 \%) \\
\end{array}$ & \\
\hline Bóc tuyến & $36(94,7 \%)$ & $2(5,3 \%)$ & $35(92,1 \%)$ & $2(5,3 \%)$ & $1(2,6 \%)$ & $38(100 \%)$ & \\
\hline $\begin{array}{l}\text { Rạch thoát } \\
\text { dịch }\end{array}$ & $\begin{array}{c}2 \\
(66,7 \%)\end{array}$ & $\begin{array}{c}1 \\
(33.3 \%)\end{array}$ & $\begin{array}{c}2 \\
(66,7 \%)\end{array}$ & $\begin{array}{c}1 \\
(33,3 \%)\end{array}$ & $\begin{array}{c}0 \\
(0 \%) \\
\end{array}$ & $\begin{array}{c}3 \\
(100 \%)\end{array}$ & \\
\hline Tổng số & $\begin{array}{c}62 \\
(87,3 \%)\end{array}$ & $\begin{array}{c}9 \\
(12,7 \%)\end{array}$ & $\begin{array}{c}62 \\
(87,4 \%)\end{array}$ & $\begin{array}{c}8 \\
(11,3 \%)\end{array}$ & $\begin{array}{c}1 \\
1,4 \%) \\
\end{array}$ & $\begin{array}{c}71 \\
(100 \%) \\
\end{array}$ & \\
\hline
\end{tabular}

Nhân xét: Kỹ thuật "chích khâu viền khăn", tái phát $20 \%$, di chứng seo cứng $16,7 \%$. "Bóc tuyến", tái phát 5,3\%, di chứng đau khi giao hợp 2,6\%; sẹo cứng 5,3\%. "Rạch thoát dịch", tái phát $33,3 \%$, di chứng sẹo cứng $33,3 \%(p<0,05)$.

\section{BÀN LUẬN}

Trong nghiên cứu của chúng tôi, tuổi của bệnh nhân từ 15 đến 58 ; trung bình $37,2 \pm 1,1$ tuổi. Điều này tương tự nghiên cứu của Jin-Sung Yuk, với tuối trung bình là $38,1^{3}$. Ở bảng 1 , những bệnh nhân từ 20 đến 49 tuổi chiếm chủ yếu $84,3 \%$. Đây là độ tuổi sinh sản của phụ nữ, điều này cho thây: tổn thương nang, áp-xe tuyến Bartholin hay găp ở phụ nữ trong độ tuổi sinh sản. Sau 50 tuổi, tỷ lẹ mắc bệnh giảm, chỉ còn $11,4 \%$. Theo nghiên cứu của Jin-Sung Yuk, ở những phụ nữ trẻ tuổi, lượng dịch âm đạo và dịch tuyến Bartholin nhiều hơn so với phụ nữ sau tuổi mãn kinh. Nên nguy cơ bị lấp đầy bởi dịch, để tạo thành bệnh lý tuyến Bartholin ở người tré cao hơn phụ nữ sau mãn kinh. Ngoài ra, nồng độ hoocmon Estrogen giảm liên quan tới tuổi, cũng dẫn tới giảm tiết dịch và giảm bôi trơn các cơ quan sinh dục ngoài nên giảm nguy cơ mắc bệnh ${ }^{3}$.

Có triệu chứng "đau" chiếm tỷ lệ cao nhất $78,6 \%$ (bảng 2). Triệu chứng này cũng cao nhất trong những bệnh nhân áp-xe tuyến Bartholin; tiếp đến là có "viêm đỏ" 83,9\%; và "rò mủ" chỉ ởhình thái này. Theo GS Dương Thị Cương, dấu hiệu bắt đầu của áp-xe tuyến Bartholin là đau và nóng âm hộ một bên phía trước trên, ban đầu khu trú, sau lan tỏa. Bên trong đó chứa đầy mủ gây sưng dạng áp-xe ở đáy chậu, tầng sinh môn.
Nếu không can thiệp gì thì dẫn tới rò mủ, làm cho bệnh nhân nhẹ đi, nhưng dẫn lưu không đây đủ chính là nguồn gốc của tái phát sau này ${ }^{4}$. Trong số những bệnh nhân nang tuyến Bartholin, có triệu chứng "sờ thấy khối" chiếm tỷ lệ cao nhất 92,1\%. Nang tuyến Bartholin (đúng hơn là "nang ống tuyến Bartholin") do sự bít tắc ống dẫn của tuyến, làm dịch ứ lại, ống tuyến giãn ra hình thành khối nang. Nếu có nhiễm khuẩn, tạo thành áp-xe tuyến Bartholin². Vì vậy, các nang tuyến Bartholin trên lâm sàng khám chủ yếu dựa vào tính chất khối nang. Có triệu chứng sốt chiếm $9,7 \%$ trên tổng số bệnh nhân. Điều này tương tựnghiên cứu của H.Krissi, A.Shmuely (2015) với tỷ lệ trường hợp có sốt là $12,7 \%{ }^{5}$. Sở dĩ trong nghiên cứu của chúng tôi, tỷ lệ bệnh nhân có sốt thấp do ổ nhiễm khuẩn khu trú, ít khi ảnh hưởng tới toàn thân; và một số trường hợp sử dụng kháng sinh trước khi nhập viện. Còn tỷ lệ tăng bạch câu là 35,7\% trong tổng số bệnh nhân, chủ yếu tăng trong các trường hợp áp-xe $61,3 \%$, phản ánh tình trạng viêm tuyển Bartholin cấp tính. Phù hợp vớinghiên cứu của H.Krissi, A.Shmuely (2015), có 55,8\% các trường hợp áp-xe tuyến Bartholin bạch cầu tăng ${ }^{5}$.

Tại bệnh viện PSTÚ, áp dụng 3 thủ thuật điều trị cho các bệnh nhân nang, áp-xe tuyến Bartholin, bao gồm: chích khâu viền khăn, bóc 
tuyến, rạch thoát dịch. Có $97,4 \%$ bệnh nhân nang tuyến Bartholin được "bóc tuyến". Trong nghiên cứu của tác giả C. Cardaillac (2019) tại Pháp, điều trị nang tuyến Bartholin, tỷ lệ bóc tuyến là $69,3 \%{ }^{6}$. Có sự khác biệt lớn trong tỷ lệ "bóc tuyến" như vậy, vì nhiều quốc gia đề cao điều trị bảo tồn, chỉ bóc bỏ khi bệnh tái phát nhiều lần hoăc trong những trường hợp nghi ngờ ung thư tuyến Bartholin.Trong bảng 3, điều trị bệnh nhân áp-xe, thủ thuật "chích khâu viền khăn" chiếm 90,3\%; "rạch thoát dịch" 9,7\%. Tỷ lệ này tương đồng với nghiên cứu của $\mathrm{H}$. Krissi, A. Shmuely (2015) 80,9\%; đặt Word catheter $19,1 \%$ trong tổng số trường hợp. Các thủ thuật điêuu trị bệnh lý tuyến Bartholin không ngừng được cải tiến: đặt Word catheter, Jacob's ring, $\mathrm{CO}_{2}$ laser,... để đơn giản trong khâu vô cảm, có thể thực hiện ở phòng khám; tuy nhiên chỉ có $3 \%$ các bác sĩ biết đến và áp dụng các phương pháp điêu trị khác ngoài 3 thủ thuật trên tại cơ sở của hộ. Còn một lý do nữa để thủ thuật "bóc tuyến" hạn chế thực hiện, đó là những tai biến xảy ra trong quá trình bóc. Ởbảng 4, chúng tôi đã thống kê: "chảy máu sau mô" $(2,6 \%)$, và "tụ máu sau mô" $(2,6 \%)$, như vây tỳ lệ tai biến trong bóc tuyến là $5,2 \%$. Ớ một tổng quan hệ thống (2009), tụ máu và chảy máu trong bóc tuyến Bartholin từ $2 \%$ đến $8 \% 7$. Theo Giáo sư Dương Thị Cương (1996) sự bóc tách từ phía trong ra phía ngoài, từ chỗ ít mạch máu ra chỗ nhiêu mạch máu, nên đường rạch là trong niêm mạc âm đạo. Gặp những trường hợp viêm nhiễm rất khó tìm thấy bình diện bóc tách. Đặc biệt là phía trên, phía ngoài và phía trước có "cơ hành xốp" làm cho sự cầm máu khó khăn. Biến chứng của phẫu thuật này là tụ máu ở tầng sinh môn, đôi khi rất to ${ }^{4}$.

Bảng 5 chỉ ra, tỷ lê tái phát chung là 12,7\%; tái phát trong từng kỹ thuật: "rạch thoát dịch" $33,3 \%$, "chích khâu viền khắn" $20 \%$, "bóc tuyến" tái phát ít nhất $5,3 \%$. Những số liệu này, phù hợp nghiên cứu của Marzano (2004) ${ }^{1}$, tỳ lệ tái phát "chích khâu viên khăn" 2\%-25\%; Ellen Wechter (2009)7, tái phát "rạch thoát dịch" 0\%$38 \%$, bóc tuyến $0 \%-3 \%$. Đối với áp-xe tuyến Bartholin, việc bóc bỏ hoàn toàn tuyến là khó khăn do tình trạng viêm nhiễm lan tỏa, nên ở nghiên cứu của chúng tôi, tất cả bệnh nhân ápxe không có trường hợp nào được bóc tuyến. Khi điều trị áp-xe bằng các phương pháp bảo tồn tuyến, thì vẫn còn khả năng tái phát. Năm 2019, nghiên cứu hồi cứu 7 năm của tác giả Reut Rotem, chỉ ra: tìm thấy tỷ lê dương tính với vi khuẩn E.Coli cao hơn đáng kể ở những phụ nữ bị tái phát tổn thương tuyến Bartholin. Có thể, sự tái phát liên quan đến loại vi khuẩn ${ }^{8}$. Di chứng sẹo cứng sau"chích khâu viền khăn" là 16,7\%, sau "bóc tuyến" 5,3\%. Sở dĩ di chứng "sẹo cứng" chiếm phần lớn ở nhóm bệnh nhân được "chích khâu viền khăn", vì quy trình thực hiện thủ thuâat: khâu một vài mũi catgut 20 để giữa vỏ tuyến, da và niêm mạc tạo thành một túi thông ra ngoài. Chính những mũi khâu này làm cho quá trình tái tạo biểu mô, lành vết thương và hình thành sẹo cứng. Đối với bóc tuyến, việc lấy đi hoàn toàn tuyến làm mất chức năng tiết dịch trong quá trình giao hợp, nên chúng tôi đã ghi nhận 2,6\% bênh nhân "đau khi giao hợp" sau bóc. Một nghiên cứu thử nghiệm ngẫu nhiên: chức nằng tình dục sau điều trị áp-xe tuyến Bartholin, bằng 2 thủ thuật: bóc tuyến và chích khâu viền khăn. Tác giả dùng chỉ số chức năng tình dục ở người phụ nữ (FSFI) để đánh giá theo điểm. Theo đó, ở cả 2 thủ thuật thì FSFI đều thấp hơn mức bình thường; và thấp hơn ở nhóm "chích khâu viền khăn" (22,33 $\pm 5,11$ so với $24,76 \pm 4,32$ ở nhóm bóc tuyến). Và tác giả kết luận rằng bóc tuyến ít ảnh hưởng đến chức năng tình dục ở người phụ nữ hơn so với chích khâu viền khăn ${ }^{8}$.

\section{KẾT LUÂNN}

Bệnh lý nang, áp-xe tuyến Bartholin hầu hếtxảy ra trong độ tuổi sinh sản; "đau" là triệu chứng lâm sàng phổ biến nhất. Thủ thuật "bóc tuyến" chiếm tỷ lệ cao 97,4\% trong điều trị nang tuyến Bartholin; với tỷ lệ tái phát thấp $(5,3 \%)$ và di chứng đau khi giao hợp với tỷ lệ thấp 2,6\%. "Chích khâu viền khăn" chiếm tỷ lệ chủ yếu 90,3\% trong điều trị áp-xe tuyến Bartholin, với tỷ lệ tái phát cao $20 \%$ và di chứng nhiêu hơn so với thủ thuật bóc tuyến.

\section{TÀI LIÊU THAM KHẢO}

1. David A.Marzano, Hope K.Haefner. The Bartholin gland cyst: past, present, and future. Journal of Lower Genital Tract Disease. July 2004;8:195-204.

2. Purdir J, Auld BJ.A review of the management of diseases of the Bartholin' gland.Journal of Obstetrics and Gynaecology. Feb 2008;28(2):701-703.

3. Jin-Sung Yuk. Incedence of Bartholin duct cysts and abscesses in the Republic of Korea.International Journal of Gynecalogy and Obstetrics.2013;122:62-64.

4. Dương Thị Cương. Ba trường hợp điều trị u nang tuyến Bartholin bằng khâu lộn túi. Tạp chí y học thực hành. 1996; số 6.

5. Krissi H, Shmuely A. Acute Bartholin's abscess: microbial spectrum, patient characteristics, clinical manifestation, and surgical outcomes.Eur J Clin Microbiol Infect Di. 2015;35:443-446. 
6. Cardaillac, Claire. Surgical management of Bartholin cysts and abscesses in French university hospitals.Journal of gynecology obstetrics and human reproduction. 2019;48(8): 631-635.

7. Wechter ME. Management of Bartholin duct cysts and abscesses: a systematic review. Obstet
Gynecol Surv. 2009;64(6):395-404.

8. RotemR. Risk factors associated with recurrent referral to the emergency room following surgical treatment of Bartholin's gland abscess.Journal of Obstetrics and Gynaecology. 2020;40(1):111-115.

\title{
GIÁ TRỊ CỦA SIÊU ÂM KẾT HỢP ĐÀN HỒI MÔ TRONG CHẨN ĐOÁN UNG THƯ TUYẾN TIỀN LIỆT
}

\author{
Đoàn Thị Nga ${ }^{1}$, Nguyễn Lan Hương ${ }^{2}$, Nguyễn Duy Hùng ${ }^{1,2}$, \\ Lê Thanh Dũng ${ }^{2}$, Nguyễn Duy Huề
}

\section{TÓM TẮT}

Mục tiêu: đánh giá giá trị của siêu âm kết hợp đàn hồi mô trong chẩn đoán ung thư tuyến tiền liệt (UTTTL). Đối tượng và Phương pháp: 74 bệnh nhân nghi ngờ UTTTL được siêu âm qua đường trực tràng đa phương tiện gồm 2D, Doppler màu và $S E$, được đối chiếu với kết quả giải phâu bệnh qua sinh thiết hệ thống 12 mẫu dưới hướng dẫn siêu âm qua đường trực tràng tại bệnh viện Hữu nghị Việt Đức từ tháng $5 / 2020$ đến tháng $6 / 2021$. Kết quả: Nghiên cứu có $28 / 74$ bệnh nhân ung thư $(38 \%)$, phát hiện $78 / 296$ tổn thương ung thư ở 2 vùng chính là vùng ngoại vi (36) và vùng chuyển tiếp (42).Trong chẩn đoán UTTTL nằm ở vùng ngoại vi, siêu âm 2D, 2D+Doppler màu, 2D+Doppler màu+SE có độ nhay lần lượt là $72.2 \%, 72.2 \%, 80.6 \%$. Trong chẩn đoán UTTTL nằm ở vùng chuyển tiếp, siêu âm 2D, 2D+Doppler màu, 2D+Doppler màu+SE có độ nhạy lần lượt là 40.5\%, 66.7\%, 85.7\%. Kết luận: Siêu âm 2D qua đường trực tràng có độ nhạy cao trong chẩn đoán UTTTL nằm ở vùng ngoại vi nhứng có độ nhạy thấp trong chẩn đoán UTTTL nằm ở vùng chuyển tiếp. Kết hợp hai hoă̆c ba kĩ thuật siêu âm đều làm tăng độ nhay trong chẩn đoán UTTTL đặc biệt ở vùng chuyển tiếp.Siêu âm đàn hồi mô là phương pháp bố trợ giúp làm tăng đôn nhay trong chẩn đoán UTTTL.

Tư khóa: ung thư tuyến tiền liệt, siêu âm qua đường trực tràng, siêu âm kết hợp đàn hồi mô.

\section{SUMMARY}

\section{VALUES OF ULTRASOUND ASSOCIATED ELASTOGRAPHY IN THE DIAGNOSIS OF PROSTATE CANCER}

Purpose: This study aims to evaluate the value of ultrasound associated elastography in the diagnosis of prostate cancer. Material and Method: 74 patients with suspected prostate cancer was performed transrectal multiparametric ultrasound includes 2D,

\footnotetext{
${ }^{1}$ Trường đại học Y Hà Nội,

²Bệnh viện Hữu nghi Việt Đức

Chịu trách nhiệm chính: Đoàn Thị Nga

Email: Doannga0226@gmail.com

Ngày nhận bài: 4.8.2021

Ngày phản biện khoa học: 5.10.2021

Ngày duyệt bài: 14.10.2021
}

color Doppler and elastography, was compare with Histological results follow transrectal US guide system biopsy12 core at the Viet Duc Hospital from May 2020 to June 2021. Results: This study has $28 / 74$ patients with prostate cancer (38\%), detect 78/296 cancer lesions located in two main zones are peripheral zone (36) and transition zone (42). Diagnosis cancer in peripheral zone on 2D, 2D+color Doppler, 2D+color Doppler+SE has sensitivity of $72.2 \%, 72.2 \%, 80.6 \%$, respectively. Diagnosis cancer in transition zone on 2D, 2D+color Doppler, 2D+Doppler+SE has sensitivity of $40.5 \%, 66.7 \%, 85.7 \%$. Conclusion: Transrectal ultrasound $2 \mathrm{D}$ has high sensitivity in the diagnosis prostate cancer in the peripheral zone and low sensitivity in the diagnosis prostate cancer in the transition zone. To combine two or three technical ultrasound increase the sensitivity in diagnosis prostate cancer, especially in transition zone. Sonoelastography is supplement way to increase sensitivity in the diagnosis prostate .

Keywords: prostate cancer, transrectal ultrasound, ultrasound associated elastography.

\section{I. ĐẶT VẤN ĐỀ}

Ung thư tuyến tiên liệt (UTTTL) là loại ung thư thường gặp nhất và là nguyên nhân gây tử vong thứ tư do ung thư ở nam giới ${ }^{1}$. UTTTL có tỉ lệ sống sau 5 năm là $100 \%$ nếu được phát hiện sớm ở giai đoạn còn khu trú, tuy nhiên, ở giai đoạn đã có di căn, tỉ lệ này giảm xuống chỉ còn $32 \%$, do đó việc chẩn đoán sớm và điều trị kịp thời có vai trò rất quan trọng.

Siêu âm là phương pháp chẩn đoán cơ bản và đâuu tay trong chẩn đoán UTTTL nhưng hiện nay chưa có một kĩ thuật siêu âm riêng lẻ nào được coi là tối ưu, do vậy sinh thiết hệ thống dưới hướng dẫn của siêu âm qua đường trực tràng vẫn là phương pháp được lựa chọn để chẩn đoán xác định UTTTL ở những bệnh nhân có PSA> $4 \mathrm{ng} / \mathrm{ml}^{2}$. Siêu âm TTL qua đường trực tràng (TRUS) đã khắc phục được những nhược điểm của siêu âm qua đường bụng và là phương pháp chính trong phát hiện các tổn thương của TTL. TRUS bao gồm đồng thời siêu âm 2D và siêu âm Doppler, ngay nay còn được bổ sung thêm siêu 